\title{
$\begin{array}{lllllllll}\mathrm{I} & \mathrm{N} & \mathrm{S} & \mathrm{T} & \mathrm{I} & \mathrm{T} & \mathrm{U} & \mathrm{T} & \mathrm{E}\end{array}$
}

\section{Children in Central Cities and Rural Communities Experience High Rates of Poverty}

$\mathrm{O}$ n August 26, 2008, the U.S. Census Bureau released new data on child poverty showing that over 13 million children are living in poverty, $22 \%$ of rural children and $25 \%$ of children living in central cities. On average, rates are persistently higher in rural parts of the country relative to suburban areas and share similar rates with many central cities. The child poverty rate is the most widely used indicator of child well-being because poverty is closely linked to undesirable outcomes in areas such as health, education, emotional welfare, and delinquency.

Table 1 shows child poverty rates for each state by level of urbanization, and how child poverty rates vary by place size within and across states. Release of data from the Census Bureau's new American Community Survey (ACS) provide state-by-state measures of child poverty, useful for crosssectional comparisons.

The data shown here are based on the official poverty measure as determined by the U.S. Office of Management and Budget. The official poverty measure consists of a series of income thresholds based on family size and composition. The 2007 poverty level was $\$ 21,027$ for a family of two adults and two children.

\section{A U T H O R}

Sarah Savage (sarah.savage@unh.edu) is a research assistant at the Carsey Institute and a Ph.D. candidate in sociology at the University of New Hampshire.

This fact sheet is available online at http://www.carseyinstitute.unh. edu/publications/FS_RuralChildPoverty_08.pdf.

\section{Key results include:}

- At the national level, the rural child poverty rate of $22 \%$ is 9 percentage points higher than in suburban areas and approaches the rate in central cities (25\%).

- In 17 states, rural child poverty is higher than rates in both suburban and urban areas.

- The rural child poverty rate in 2007 ranges from a low of just 7\% in Connecticut to a high of 35\% in Mississippi.

- 13 southern states have rural child poverty rates above $25 \%$ in 2007, which reflects the pervasive child poverty problem in the rural South. This trend is consistent with 2005 data.

- The state with the biggest percentage point discrepancy between rural rates of child poverty relative to suburban is Mississippi (18 percentage points higher in rural), followed by Arizona and South Dakota (15 percentage points) and Louisiana (14 percentage points).

- The state with the biggest percentage point discrepancy between rural rates of child poverty relative to urban is Alaska (10 percentage points higher in rural), followed by Arizona ( 9 percentage points), and Vermont (8 percentage points).

- No states ${ }^{1}$ show lower rates of child poverty in rural than suburban areas, but 28 states have lower rates of rural child poverty than urban areas, led by Delaware with a rate of 22 percentage points lower in rural than in urban areas.

- Relative to 2005 ACS data, in 2007, 5 states (Utah, Wyoming, Colorado, Louisiana, and Tennessee) show increases of 2 percentage points or more in the rural child poverty rate.

${ }^{1}$ The rate of child poverty in Connecticut is higher in suburban than rural areas but by a negligible amount ( 0.1 percentage points).

\section{CARSEY INS TITU T E}

Building KNOWLEDGE FOR Families and Communities IN THE 21ST CENTURY
Huddleston Hall, 73 Main Street, Durham, NH 03824

(6o3) 862-2821 • www.carseyinstitute.unh.edu
UNIVERSITY of NEW HAMPSHIRE
The Carsey Institute Reports on Rural America are supported by the Annie E. Casey Foundation's initiative to strengthen rural families, the Ford Foundation, and the W.K. Kellogg Foundation. 
Table 1. Child Poverty by Place Size ${ }^{1}$ In 2007

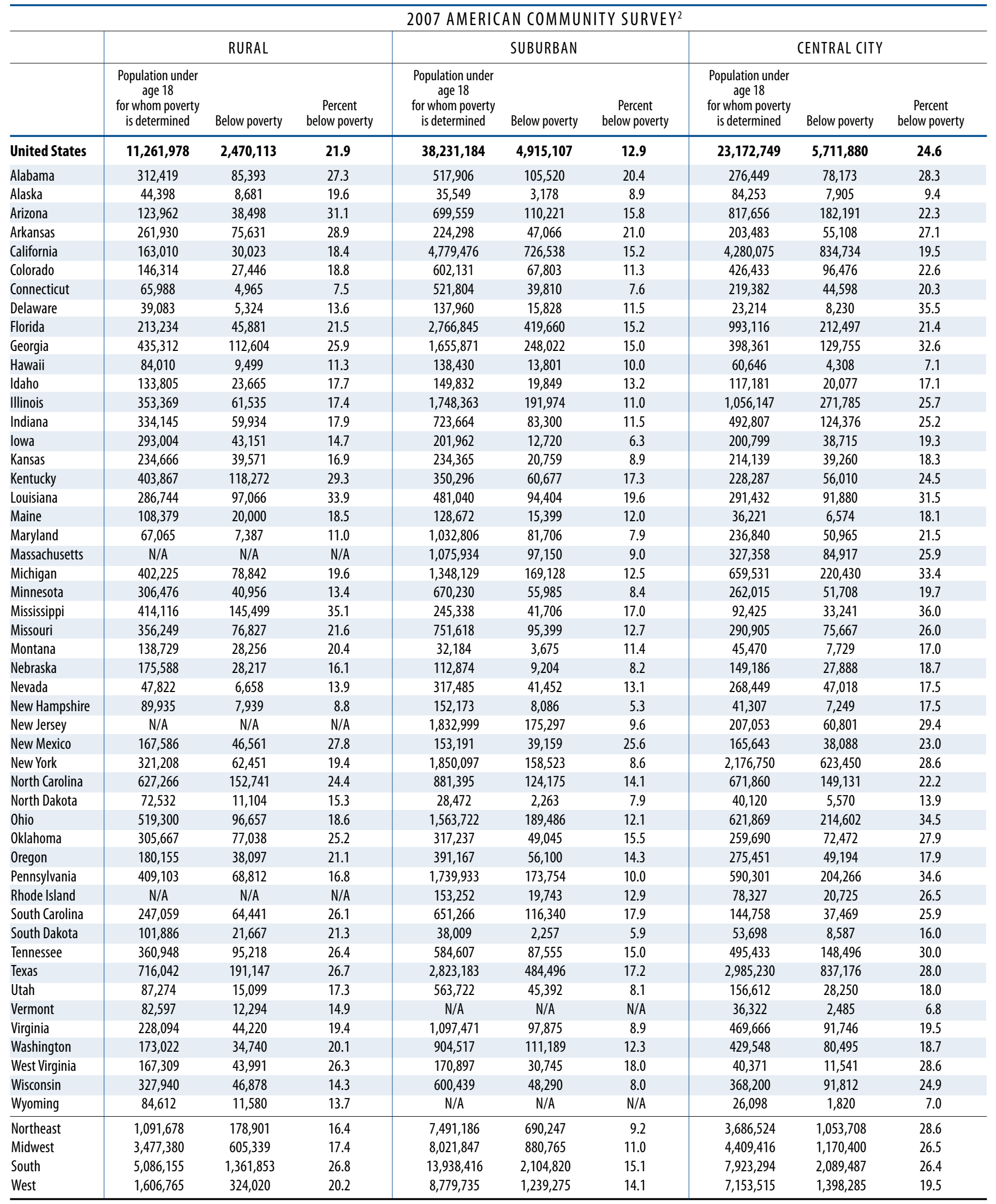

$\mathrm{N} / \mathrm{A}=$ Not applicable.

'Levels of urbanization are defined as follows: rural consists of ACS geographic components "Not in metropolitan or micropolitan statistical area" and "In micropolitan statistical area"; suburban includes "In metropolitan statistical area — not in principal city" and central city includes "In metropolitan statistical area—in principal city".

2Data are based on 2007 American Community Survey estimates. For corresponding margins of error, refer to the US Census American Community Survey. 